\title{
Cardiac intervention procedures in the United Kingdom 1997: developments in data collection
}

\author{
M A de Belder, on behalf of the Council of the British Cardiovascular Intervention Society
}

Council of the British Cardiovascular Intervention Society E J Perrins (president) M Norell (secretary) P Silverton (treasurer) M A de Belder (audit secretary) S W Davies K D Dawkins R J C Hall D Ramsdale D Roberts P Schofield L D R Smith

Audit Subcommittee M A de Belder

H H Gray

L D R Smith

A F R Rickards

(co-opted)

Correspondence to: Dr M A de Belder, South Cleveland Hospital, Marton Road, Middlesbrough, TS4 3BW, UK.

Table 1 Procedures in NHS centres 1997

\begin{tabular}{|c|c|c|}
\hline & 1996 & 1997 \\
\hline Mean number of adult catheter sessions per week & 16.1 & 15.7 \\
\hline Mean annual number of adult diagnostic angiograms per centre & 2087 & 2547 \\
\hline Mean annual number of adult intervention procedures per centre & 460 & 475 \\
\hline $\begin{array}{l}\text { Mean number of consultant cardiologists undertaking diagnostic } \\
\text { catheterisation }\end{array}$ & 7.6 & 7.7 \\
\hline $\begin{array}{l}\text { Mean number of junior cardiology staff undertaking diagnostic } \\
\text { catheterisation }\end{array}$ & 6.3 & 6.3 \\
\hline $\begin{array}{l}\text { Mean number of radiologists (consultant and junior) undertaking } \\
\text { diagnostic catheterisation }\end{array}$ & 0.7 & 0.6 \\
\hline Mean number of trained cardiology interventionists per centre & 6.7 & 6.2 \\
\hline Mean number of consultant radiology interventionists & 0.3 & 0.13 \\
\hline
\end{tabular}

Table 2 Procedures in private centres 1997

\begin{tabular}{lll}
\hline & 1996 & 1997 \\
\hline Mean number of adult catheter sessions per week & 9 & 9.5 \\
Mean number of adult diagnostic angiograms per year & 909 & 734 \\
Mean number of adult intervention procedures per year & 137 & 183 \\
Mean number of consultant cardiologists undertaking diagnostic & 17.7 & 18 \\
$\quad$ catheterisation & & 3.2 \\
Mean number of consultant radiologists undertaking diagnostic & 3.3 & 8.3 \\
$\quad$ catheterisation & 6.0 & 3 \\
Mean number of trained PCI cardiology interventionists & 3.5 & \\
\hline
\end{tabular}

used for some years, was sent to determine levels of activity as well as facilities and staffing. In addition, a modified form was sent in an attempt to provide more accurate outcome data on patients undergoing procedures. Although BCIS is ultimately committed to collect follow up data up to five years after a coronary intervention, outcome information relating only to the period of hospitalisation for the procedure was asked for. As before, this was an entirely voluntary exercise, with no specific funding. It is accepted that each unit has its own way of collecting data and there was no attempt by BCIS to instruct units in this matter. Information was sought on variables accepted as indicating major adverse cardiac events - that is, death, development of $\mathrm{Q}$ wave myocardial infarction, and the requirement for emergency coronary artery bypass grafting (CABG). There was no attempt at data validation.

\section{Results}

A. NATIONAL STRUCTURE FOR CARDIAC INTERVENTIONS

Number of centres

The number of units performing PCI in 1997 was 58 (45 National Health Service (NHS) hospitals and 13 private hospitals). This is a growth of five centres (four NHS, one private) compared with 1996. All these centres also perform diagnostic cardiac catheterisation. Another 32 centres were identified which performed diagnostic but not intervention procedures.

\section{Diagnostic procedures}

Those centres performing only diagnostic procedures have, to date, not been sent questionnaires and thus the only information obtained relates to diagnostic procedures performed in the intervention centres (tables 1 and 2). Thirteen of the 45 NHS centres (29\%) and six of the 13 private centres (46\%) did not provide details of the numbers of diagnostic catheters performed. The remaining 39 centres reported 86633 diagnostic cardiac catheterisation procedures (in NHS centres mean 2547, range $807-5251$; in private centres mean 734, range 233-1222). This represents a $22 \%$ increase in diagnostic activity in the NHS centres between 1996 and 1997. Comparison with 1996 data is, however, difficult in that several new centres clearly had a very low activity while the merger of some units created large volume centres. The apparent 19\% reduction in the mean activity in the private centres probably reflects a lack of accurate data and the inclusion of data from a new relatively low volume centre. Of all diagnostic 
procedures, $6 \%$ were performed in private centres but this does not reflect the total private activity as the data from many NHS units include private work.

For those centres providing data for both, the ratio between diagnostic and intervention procedures was 5.23:1. The average for NHS centres was 5.3:1 (range 2.8-111). The centre with a ratio of 111:1 was a diagnostic centre which only started performing angioplasty at the end of the year. Another centre performing diagnostic procedures and only emergency angioplasty had a ratio of $33: 1$. The range for the others was 2.8-9.2. In the private hospitals the ratio was 7.4:1 (range 5-39). The mean number of weekly sessions available for diagnostic and intervention work was 16 in the NHS hospitals (range 6-30) and 9.5 for private centres (range 5-16).

The increase in diagnostic workload compared to 1996 was undertaken without any significant growth in the number of consultants or juniors. As not all centres reported their staffing levels, the total number of operators cannot be determined. However, in the NHS hospitals reporting, the mean number of cardiologists per centre for diagnostic work was 7.6 in 1996 and 7.7 in 1997 (range 2-22). The mean number of cardiologists in training was 6.1 (range 0-14), compared to 6.3 in 1996. The fall in the mean reflects in part the lack of juniors in new centres. There is no evidence to suggest an overall change in the number of trainees. Although eight NHS centres did not provide data, the others reported a total of 225 junior cardiologists performing diagnostic work, 64 senior registrars, and 161 specialist registrars. Consultant radiologists were per-

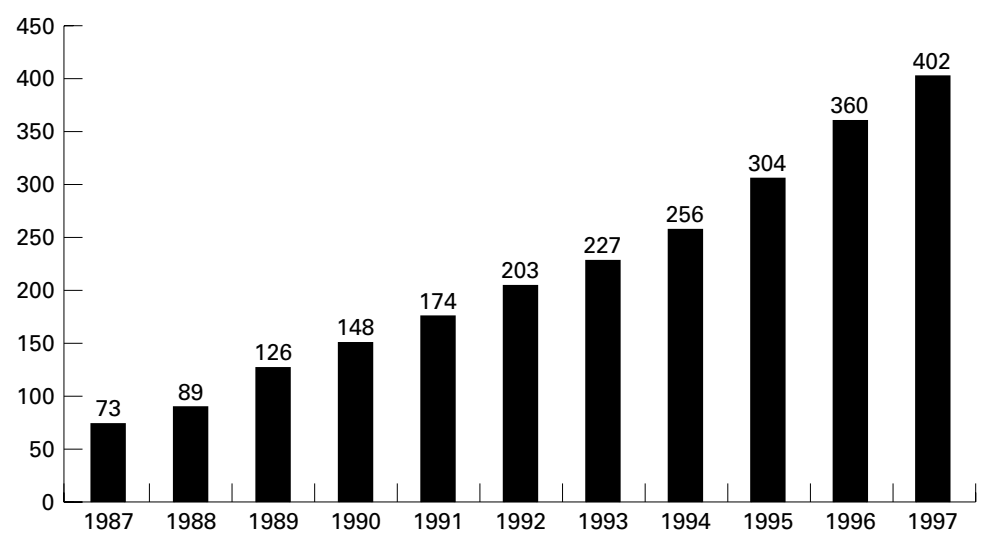

Figure 1 PCI procedures per million UK population.

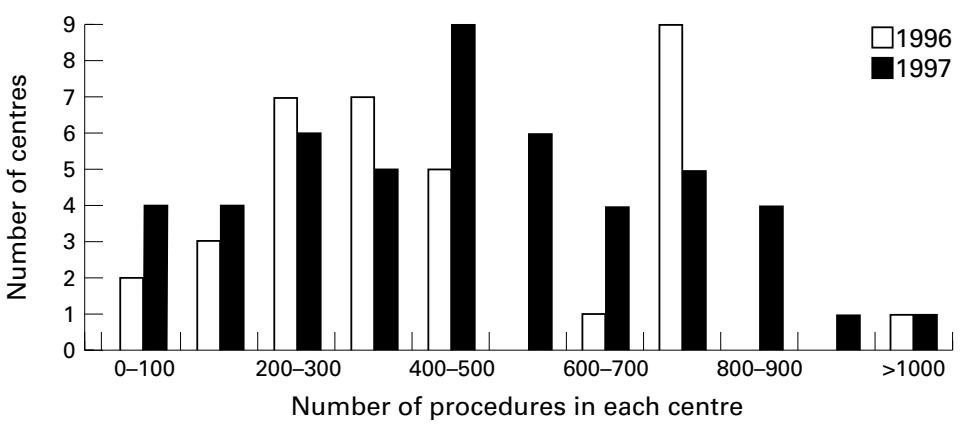

Figure 2 Total number of procedures per annum in NHS centres. forming diagnostic work in only 10 of the NHS centres, and only eight junior staff in radiology were identified as trainees in cardiac diagnostic procedures.

Number of intervention procedures

One NHS centre (King Edward VIIth Hospital, Midhurst) and two private centres (HCI Glasgow and the BUPA Hospital, Bristol) provided no data at all. The other 55 centres reported a total of 22902 coronary interventions, 20885 (91\%) being performed in NHS hospitals. This compares with a total of 20511 reported in 1996, and represents an annual increase of $11.7 \%$. This is a slightly smaller growth in PCI than in the two previous years $(18.6 \%$ and $18.1 \%$, respectively). The national number of reported interventions per million population for 1997 was 402 (fig 1). The mean activity for NHS centres was 475 (range 9-1400), compared to 460 in 1996 (table 1). The mean activity for private centres was 183 (range 14-457) compared to 137 in 1996 (table 2).

The range of activity between centres is outlined in fig 2. The majority of centres performed over 500 PCIs per annum. There were eight centres performing fewer than 200 per annum, but of these four were new centres only starting their intervention programmes in 1997. Two of the larger units represent units which merged in 1997. Compared with 1996 there is a slight shift of the distribution curve to the right consistent with a growth in activity in all units. There was no increase in the ratio between single and multivessel angioplasty. In those centres providing data, $16 \%$ of cases were multivessel procedures.

The mean number of cardiology consultant interventionists per NHS centre was 4.7. In the 37 centres providing data there were 173 intervention cardiologists and five consultant radiologists performing angioplasty. Assuming that each consultant either performed every case or was directly responsible for the procedure, the mean level of activity was 101 patients per consultant. In these centres 46 senior registrars in cardiology and five specialist registrars were identified as training in angioplasty. No junior radiologists were identified as training in intervention.

\section{B. APPROPRIATENESS OF INTERVENTION}

The BCIS data collection to date has not been designed to evaluate the appropriateness of procedures - that is, the indications for intervention. Some data relating to coronary syndromes are summarised in section D.

\section{PROCESS}

Types of coronary procedure

The previously reported growth in stent procedures continued in 1997, with $60 \%$ of all cases being treated with this modality (data from 47 centres) (fig 3). Although all centres used stents, the range between centres was large (18-99\%).

The mean number of stents per case was 1.05, suggesting that single lesion stenting was the most common procedure (data from 34 centres). Centres were also asked to identify 


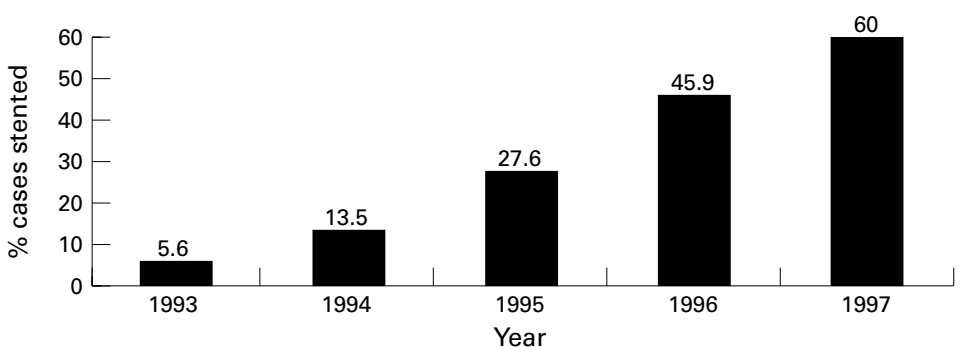

Figure 3 Use of stents from 1993 to 1997.

Table 3 Use of other intervention devices 1997

\begin{tabular}{lllllll}
\hline & PTCRA & DCA & TEC & Laser & $\begin{array}{l}\text { Cutting } \\
\text { balloon }\end{array}$ & Acolysis \\
\hline Centres & 17 & 8 & 5 & 1 & 8 & 1 \\
Number of cases & 154 & 46 & 12 & 13 & 49 & 12 \\
Mean & 9 & 5.8 & 2.4 & - & 6.1 & - \\
Range & $1-76$ & $1-16$ & $1-5$ & - & $1-36$ & -
\end{tabular}

PTCRA, percutaneous transluminal coronary rotational atherectomy; DCA, directional coronary atherectomy; TEC, transluminal extraction catheter.

Table 4 Valvuloplasty procedures and angioplasty for aortic coarctation 1997

\begin{tabular}{llllll}
\hline & $\begin{array}{l}\text { Mitral } \\
\text { valve plasty }\end{array}$ & $\begin{array}{l}\text { Aortic } \\
\text { valve plasty }\end{array}$ & $\begin{array}{l}\text { Pulmonary } \\
\text { valve plasty }\end{array}$ & $\begin{array}{l}\text { Tricuspid } \\
\text { valve plasty }\end{array}$ & $\begin{array}{l}\text { Coarct/ } \\
\text { recoarct }\end{array}$ \\
\hline Centres & 30 & 5 & 12 & 2 & 4 \\
Number of cases & 238 & 9 & 21 & 2 & 8 \\
Mean & 7.9 & 1.8 & 1.75 & - & 2 \\
Range & $1-26$ & $1-2$ & $1-5$ & - & $1-4$ \\
\hline
\end{tabular}

Coarct/recoarct, aortic coarctation/restenosed coarctation.

Table 5 Other procedures 1997

\begin{tabular}{lllll}
\hline & Centres & $\begin{array}{l}\text { Number } \\
\text { of cases }\end{array}$ & Mean & Range \\
\hline Patent ductus arteriosus & 2 & 16 & - & $1-15$ \\
Atrial septal defect & 5 & 17 & 3.4 & $1-7$ \\
Patent foramen ovale & - & - & - & - \\
Ventricular septal defect & 1 & 1 & - & - \\
Foreign body removal & 9 & 17 & 1.9 & $1-6$ \\
HOCM ablation & 2 & 2 & - & - \\
Balloon pericardiotomy & 2 & 13 & - & - \\
Pressure wire & 1 & 10 & - & - \\
Pulmonary artery PTA/ stenting & 1 & 1 & - & - \\
Aortic stenting & 1 & & - \\
\hline
\end{tabular}

HOCM, hypertrophic obstructive cardiomyopathy; PTA, percutaneous transluminal angioplasty.

Table 6 Reported outcomes after PCI 1991 to 1997 (excluding mortality data)

\begin{tabular}{|c|c|c|c|c|c|}
\hline Year & $\begin{array}{l}\text { Total } \\
\text { PCIs }\end{array}$ & $\begin{array}{l}\text { Vessels/ } \\
\text { case }\end{array}$ & $\begin{array}{l}\text { Angio } \\
\text { success } \\
(\%)\end{array}$ & $Q M I(\%)$ & $\begin{array}{l}\text { Emergency } \\
C A B G(\%)\end{array}$ \\
\hline 1991 & 9933 & & $86 \%$ & $1.6 \%$ & $2.6 \%$ \\
\hline 1992 & 11575 & 1.17 & $86 \%$ & $1.4 \%(10294)$ & $2.0 \%(10649)$ \\
\hline 1993 & 12937 & 1.09 & $89 \%$ & $1.1 \%(11508)$ & $2.0 \%(11508)$ \\
\hline 1994 & 14624 & 1.15 & $89 \%$ & $1.1 \%(12253)$ & $1.8 \%(12598)$ \\
\hline 1995 & 17344 & 1.17 & $89 \%$ & $1.4 \%(11365)$ & $1.9 \%(12002)$ \\
\hline 1996 & 20511 & 1.17 & $90 \%$ & $1.2 \%(14702)$ & $1.5 \%(15176)$ \\
\hline 1997 & 22902 & 1.16 & $92 \%$ & $1.4 \%(15481)$ & $1.1 \%(19269)$ \\
\hline
\end{tabular}

Angio, angiographic; MI, myocardial infarction.

Numbers in parentheses are the numbers from which the data are obtained; the difference between this number and the total procedures reported for the year relates to missing data.

whether stent usage was elective, for a suboptimal balloon angioplasty result, or in bailout circumstances. Few centres provided these data, but in an analysis of 7096 cases, $45 \%$ of cases were elective, $39 \%$ were for suboptimal results, and $14 \%$ were for bailout. This represents a continuing trend towards more elective stenting. However, the range of responses $(7.5-100 \%$ for elective, $0-98 \%$ for suboptimal, and $0-52 \%$ for bailout) suggests in part some degree of variation in interpretation of the definition of these criteria.
Debulking and other devices are only used by a few centres (table 3 ). Of these rotablation is the most frequently used device, possibly reflecting its niche role for resistant or calcified lesions and the treatment of in-stent restenosis. For those using these devices there were some with very low volume use.

\section{Non-coronary procedures}

Mitral valvuloplasty was performed in 30 centres, only one patient receiving treatment in a private centre (table 4). The range of activity in each unit performing valvuloplasty was large, with only 10 centres performing 10 cases or more. Twelve centres performed pulmonary valvuloplasty and very few aortic valvuloplasties were undertaken. Angioplasty for coarctation was performed in only eight adult patients.

The number of other procedures was small but there was a continuing interest in the use of closure devices for atrial septal defects and patent ductus arteriosus (table 5). Few centres performed procedures on adult congenital defects. Septal ablation for hypertrophic cardiomyopathy was performed in only two centres. Only one centre reported an aortic stenting procedure, suggesting that this procedure is being performed in radiology rather than cardiology departments in the UK.

\section{OUTCOME}

\section{Outcome after PCI procedures}

The reported outcome data following a coronary intervention are outlined in tables 6 and 7 and compared with the previous years. There has been no significant change in the overall reported mortality although, as will be shown, given the changing case mix and the development of infarct angioplasty, the mortality might have been expected to increase. There has been a reduction in the rate of referral for emergency CABG over the last few years and this trend was continued in 1997. Of the NHS centres providing data, all bar two referred patients for emergency surgery. These two were centres without on-site surgery; one was an established centre performing 324 procedures in 1997 and the other was a new centre which undertook only nine procedures.

As with previous years, these data have to be interpreted with some caution or even scepticism. Some centres were unable or unwilling to provide this information. Centres were asked to specify whether the outcome data related to the in-patient stay or just the procedure itself (while the patient was still in the catheter laboratory). Only 10 centres responded to this question (eight NHS hospitals, two private centres). The two private centres were reporting laboratory outcomes only. Of the eight NHS centres, six were reporting hospital outcome and two were reporting laboratory outcome only.

The questionnaire asked for details of patients treated in the context of acute coronary syndromes, namely unstable angina, acute myocardial infarction, and following thrombolysis. In the original BCIS dataset, the latter question related to patients who underwent angioplasty in the convalescent phase of 
Table 7 Reported mortality following PCIs 1991 to 1997

\begin{tabular}{lllll}
\hline & $\begin{array}{l}\text { Number } \\
\text { of centres } \\
\text { giving data }\end{array}$ & $\begin{array}{l}\text { Total } \\
\text { procedures }\end{array}$ & Mortality & Range \\
\hline 1991 & & 9933 & $0.48 \%(9071)$ & \\
1992 & $43 / 52$ & 11575 & $0.91 \%(10483)$ & $0-3.5 \%$ \\
1993 & $44 / 53$ & 12937 & $0.62 \%(11859)$ & $0-2.7 \%$ \\
1994 & $44 / 54$ & 14624 & $0.72 \%(12598)$ & $0-2.7 \%$ \\
1995 & $35 / 54$ & 17344 & $0.77 \%(12002)$ & $0-3.4 \%$ \\
1996 & $37 / 53$ & 20511 & $0.84 \%(15204)$ & $0-3.2 \%$ \\
1997 & $41 / 58$ & 22902 & $0.91 \%(17577)$ & $0-10 \%$ \\
\hline
\end{tabular}

Numbers in parentheses refer to the number of patients from which the data are taken; the difference between this and the total number of procedures for the year relates to missing data.

Table 8 Mortality by acute clinical syndrome

\begin{tabular}{lclcc}
\hline Syndrome & Number & $\begin{array}{l}\text { Centres } \\
\text { with data }\end{array}$ & $\begin{array}{l}\text { \% of } \\
\text { total PCIs }\end{array}$ & Mortality \\
\hline Unstable angina & 4636 & $50 / 58$ & 20.0 & 0.9 \\
Following thrombolysis & 578 & $50 / 58$ & 2.5 & 4.5 \\
Acute myocardial infarction & 714 & $50 / 58$ & 3.1 & 11.0 \\
\hline
\end{tabular}

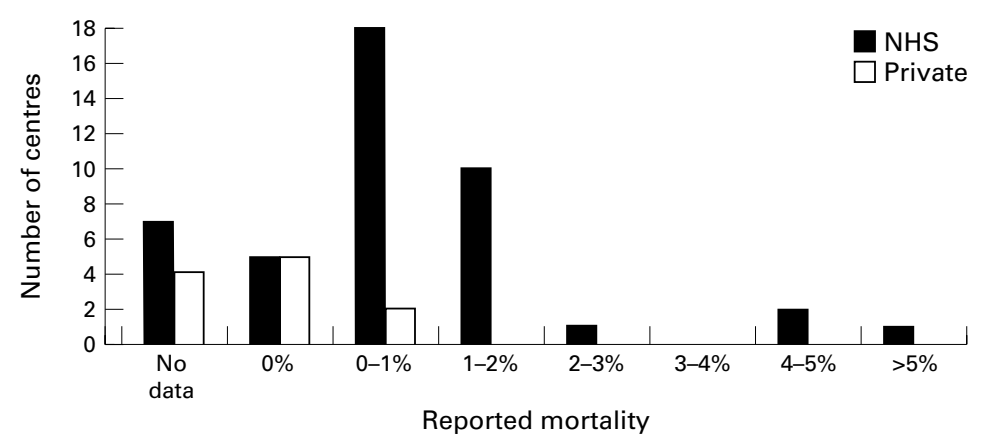

Figure 4 Distribution of reported mortality related to all PCI procedures 1997.

myocardial infarction, whereas now this variable represents a composite of these patients together with those treated with rescue (salvage) angioplasty. Accepting these difficulties, there were sufficient data to provide a broad overview of outcomes in these clinical scenarios (table 8).

Table 7, however, reveals a wide range in the reported mortality between centres which is evident in all years but is particularly obvious for 1997. Figure 4 shows the distribution of reported mortality.

Four centres had a mortality greater than $2 \%$ (table 9). They were among the centres with the most complete data, and all were reporting on hospital mortality. Centre A also provided data on 30 day mortality. These centres clearly had a very different case mix to the others, with a very large proportion of their workload relating to acute coronary syndromes. Centre A performed over $80 \%$ of its relatively low volume activity in patients with acute myocardial infarction, many of whom were in cardiogenic shock. The in-hospital mortality for cardiogenic shock patients in this centre $(23 \%)$ was lower than for the other centres. No patient treated for cardiogenic shock in centre $\mathrm{D}$ survived. The mortality for shock overall was clearly high at over $60 \%$ on average for these four centres, but this compares with an expected mortality of $80-90 \%$ for this group of patients. The mortality for stable angina and unstable angina in these centres compares favourably with the overall mortality data, although the mortality related to unstable angina in centres $C$ and $D$ is higher than in some. As the number of patients in these groups is small, however, it is not possible to compare one centre with another. Centre A also provided 30 day mortality data for all patients. Compared to the in-hospital mortality of $12 \%$, the 30 day total mortality rate was $28 \%$ for all patients treated for acute myocardial infarction ( $0 \%$ for non-shock and $54 \%$ for shock patients). Thus, outcome data vary considerably with the duration of follow up.

Thirty centres reported data on patients treated in the context of myocardial infarction, but three centres gave no outcome data (on 147 patients). Table 10 shows that this is a growing area of activity. The reported mortality of the other 1249 patients from 27 centres was $8.2 \%$. However, the variables used in the standard questionnaire did not allow for analysis of the "infarction" case mix-that is, whether a patient was in cardiogenic shock, whether the procedure was a primary angioplasty or salvage procedure, or whether it was in the convalescent phase following infarction. It can be seen that the range of mortality over the last six years has been as wide as 1997 . The low volume of these procedures in individual centres does not allow for any meaningful comparison on the basis of the data received. Figure 5 shows the reported volume of activity and procedural mortality in each centre providing data for patients treated during or after acute myocardial infarction.

The enormous range in volume of activity suggests that only a few units had a distinct policy for the role of angioplasty in the management of patients with acute myocardial infarction. The fact that some centres reported a zero or very low mortality for relatively high workloads suggests that either these units reported catheter laboratory outcome only or were performing procedures on low risk patients in the convalescent phase following myocardial infarction.

Previous reports of UK activity have summarised reported outcomes for patients treated because of graft lesions, restenosis lesions, and chronic total occlusions. Because of the difficulties in determining whether these outcomes relate to the hospital period or the procedure itself, the new forms sent out were analysed.

Table 9 Four centres with highest reported in-hospital mortality: Analysis by case mix (clinical syndrome)

\begin{tabular}{|c|c|c|c|c|c|c|}
\hline \multirow[b]{2}{*}{ Centre } & \multirow[b]{2}{*}{$\begin{array}{l}\text { Number } \\
\text { of PCIs }\end{array}$} & \multicolumn{5}{|l|}{ Mortality } \\
\hline & & $\begin{array}{l}\text { Patients with } \\
\text { stable angina }\end{array}$ & $\begin{array}{l}\text { Patients with } \\
\text { unstable angina }\end{array}$ & $\begin{array}{l}\text { All patients } \\
\text { with MI }\end{array}$ & $\begin{array}{l}\text { MI } \\
\text { with shock }\end{array}$ & $\begin{array}{l}\text { MI } \\
\text { without shock }\end{array}$ \\
\hline A & 30 & $0 \%(0 / 2)$ & $0 \%(0 / 3)$ & $12 \%(3 / 25)$ & $23 \%(3 / 13)$ & $0 \%(0 / 12)$ \\
\hline B & 500 & $0 \%(0 / 210)$ & $0 \%(0 / 128)$ & $13 \%(21 / 162)$ & $44 \%(7 / 16)$ & $9.6 \%(14 / 146)$ \\
\hline C & 189 & $0 \%(0 / 105)$ & $3.6 \%(2 / 56)$ & $29 \%(8 / 28)$ & $67 \%(6 / 9)$ & $11 \%(2 / 19)$ \\
\hline $\mathrm{D}$ & 654 & $0 \%(0 / 382)$ & $2.7 \%(5 / 187)$ & $15 \%(13 / 85)$ & $100 \%(9 / 9)$ & $5.3 \%(4 / 76)$ \\
\hline
\end{tabular}




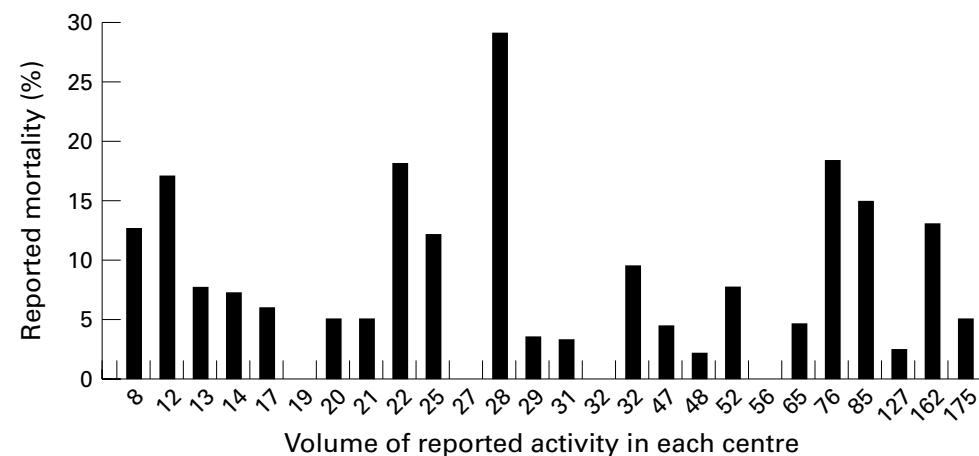

Figure 5 Patients treated during or after acute myocardial infarction. Volume of activity and mortality. the two previous years. The national activity was 402 PCIs per million population. In 1994 , the British Cardiac Society set a target of 400 per million population by the 1996-97 financial year. Growth in angioplasty has therefore been slightly slower than anticipated. At present, BCIS has not determined the number of consultants working either locally in a unit, or visiting the unit from an adjacent district hospital. These data will be collected in the future. It is essential that those clinicians performing diagnostic angiography in the district hospitals have regular meetings with both cardiac surgeons and interventionists to allow them to keep up with developments in both these specialities, in order that patients can be offered the widest and most appropriate choice in treatment.

The growth in angioplasty has been accommodated largely in the established centres, as the activity in the new centres was low. It is anticipated that these centres will increase their activity in their first few years at a rate higher than the national average. There has been no overall change in the staffing of the established centres, but new consultants have been appointed to the new centres. There has been no overall change in the number of trainees. For new centres to establish an appropriate level of staffing it will be necessary to increase the overall number of trainees in the future, redistribute those currently available, or employ more consultants.

Although the growth in angioplasty is encouraging, the UK clearly lags far behind the US and most other countries in western Europe. Some might conclude that there is excessive activity in some countries. However, the difference is so large, with some countries providing well over 1000 PCIs per million population, that this is not likely to be a convincing answer. Although waiting lists are probably unduly long in some centres, funding per se cannot be the only issue. More consultant cardiologists have been appointed to are now getting access to investigations. The growth in angioplasty was less, at $11.7 \%$, than

Table 10 Procedures in the context of myocardial infarction 1992 to 1997

\begin{tabular}{lllllll}
\hline & 1992 & 1993 & 1994 & 1995 & 1996 & 1997 \\
\hline Total procedures & 191 & 231 & 238 & 285 & 457 & 1396 \\
Number of centres & 51 & 46 & 38 & 32 & 31 & 30 \\
Mean number per centre & 4 & 5 & 6 & 9 & 15 & 47 \\
Angio success & $76 \%$ & $85 \%$ & $84 \%$ & $84 \%$ & $85 \%$ & $88 \%$ \\
CABG (\%) & $2.3 \%(172)$ & $5.2 \%(231)$ & $2.6 \%(229)$ & $6.1 \%(246)$ & $3.2 \%(376)$ & $1.1 \%(1249)$ \\
Mortality (\%) & $5.81 \%(172)$ & $4.76 \%(231)$ & $3.93 \%(229)$ & $4.88 \%(246)$ & $6.63 \%(377)$ & $8.2 \%(1249)$ \\
Range of mortality (\%) & $0-50$ & $0-31$ & $0-100$ & $0-33$ & $0-29$ & $0-29$
\end{tabular}

Numbers in parentheses refer to the number of patients from which the data were taken; the difference between this and the total number of procedures for the year relates to missing data.

Table 11 Results of units giving complete or near complete data 1997

\begin{tabular}{lllllll}
\hline & $\begin{array}{l}\text { Number of } \\
\text { patients (centres) }\end{array}$ & $\begin{array}{l}\text { Success } \\
(\%)\end{array}$ & $\begin{array}{l}\text { Repeat PCI } \\
(\%)\end{array}$ & $\begin{array}{l}\text { CABG } \\
(\%)\end{array}$ & $\begin{array}{l}\text { MI or re MI } \\
(\%)\end{array}$ & $\begin{array}{l}\text { Mortality } \\
\text { (range) }(\%)\end{array}$ \\
\hline All elective (no CTO) & $1505(7)$ & 92 & 2.2 & 0.9 & 0.8 & $0.13(0-0.27)$ \\
All elective CTO & $235(6)$ & 80 & 0.4 & 0 & 0.9 & 0 \\
Previous CABG & $270(6)$ & 85 & 0 & 0 & 1.1 & $1.1(0-10)$ \\
Restenosis & $204(6)$ & 92 & 0 & 1 & 1.5 & 0 \\
Unstable angina & $1284(7)$ & 83 & 2.8 & 0.9 & 1.2 & $1.1(0-4.8)$ \\
Acute closure & $77(7)$ & 86 & 4.0 & 4.0 & 5.2 & $9.5(0-14)$ \\
Primary PCI & $63(5)$ & 79 & 0 & 0 & 0 & $11(0-14)$ \\
Salvage PCI & $92(5)$ & 75 & 1.1 & 1.1 & 18 & $7.4(0-14)$ \\
PCI for reinfarction & $81(3)$ & 89 & 0 & 3.7 & 0 & $39(23-100)$ \\
PCI for shock & $41(5)$ & 71 & 2.4 & 7.3 & 9.8 & \\
\hline
\end{tabular}

CTO, chronic total occlusion; *patients not in shock. 
district hospitals, but the levels of staffing are not yet at the level suggested by the Royal Colleges (each hospital to have at least two consultants in each of the major specialities). It is highly likely, given that the UK has a higher incidence, prevalence, and standardised mortality ratio for coronary disease than most of these other countries, that we are still under investigating patients with ischaemic heart disease.

Coronary stenting continues to grow at a dramatic rate, with $60 \%$ of all patients being treated with stents in 1997. More stenting is being performed electively or because of suboptimal balloon angioplasty results. However, there is probably some uncertainty in some operator's minds as to what constitutes a bailout and what constitutes a use for a suboptimal result. BCIS will provide clear definitions for these different categories of use. There are other areas where uncertainties exist concerning the definition of certain variables. In general, the use of emergency CABG in the past represented a need for bailout surgery in the context of a complication of angioplasty. With an increasing use of angioplasty for acute coronary syndromes, early surgery may be required because of severe left main or triple vessel disease, but PCI will still be used initially to stabilise the patient pending complete revascularisation. BCIS will provide appropriate definitions to determine the role of surgery in this context. Similarly, the variation in survival rates for patients with myocardial infarction and especially cardiogenic shock may in part relate to different definitions of clinical syndromes. A consistent approach is required.

The area of greatest growth has been in the field of angioplasty in the context of acute myocardial infarction, with a $205 \%$ increase in activity in this area compared to 1996 . Because of this, one might have expected a change in the overall mortality figures, but overall this was $0.9 \%$ for 1997 , no real change from previous years. Further analysis of this issue reveals major problems with the present methods for data collection. Previously BCIS had asked for data relating to angioplasty used in the context of "acute myocardial infarction" and "following thrombolysis". The former does not allow differentiation between primary angioplasty, rescue ("salvage") angioplasty, angioplasty for reinfarction, angioplasty for an acute closure after a previous intervention, and certainly does not differentiate between haemodynamically stable patients and those in cardiogenic shock. The latter does not differentiate between rescue angioplasty and angioplasty used in the convalescent phase following the acute event. These will almost certainly have different natural histories and BCIS aims to refine data collection to allow for better case mix analysis.

Accordingly, the range of mortality reported in 1997 varies considerably from one centre to another, but analysis reveals that this relates primarily to differences in case mix. One centre performed only urgent angioplasty, with nearly half of all patients in cardiogenic shock. Conversely, other centres claiming to perform angioplasty for patients with acute myocardial infarction stated that none of their patients died. Although this might be possible, further analysis reveals that only a few centres provided data relating to the hospital period (as requested), many provided data only relating to the procedure itself with no information about their clinical follow up, and one centre provided data relating to 30 day mortality. To allow a national picture to emerge and to allow for a proper audit process, it will be essential for consistency. BCIS will, in the short term, be asking for data relating to the in-hospital period, and not just to whether the patient got out of the catheter laboratory. It is also clear that the mortality figures must be interpreted correctly. There is a need to differentiate between failure to change the natural history of the condition being treated and a complication of angioplasty. Those operators who are entirely honest and provide the most comprehensive data should not feel at a disadvantage.

It has been shown that the previously used method of data collection has its limitations. It has allowed BCIS to track the growth of this speciality and to monitor facilities provided. However, there is considerable inconsistency. A very small number of centres provide no data at all. There is no consistency in data relating to outcome and no clear ability to analyse case mix. There has, up to now, been no method of data verification. BCIS is aware of one centre that has performed angioplasty on some patients with cardiogenic shock but these have not been included in that centre's returns. Clinicians are apparently uneasy about how mortality figures will be interpreted by those entitled to look at the data but who may not understand them. These include purchasers of health care, the media, and patients themselves. BCIS is resolved to improve data collection to establish the most appropriate method of performing audit.

In 1997, an attempt was made to determine hospital mortality for certain syndromes, but only a minority of centres could provide complete data. The results shown in table 11 give us a much clearer picture of the outcomes to be expected for patients undergoing angioplasty. The mortality results provided for infarct angioplasty are, perhaps, higher than might be expected. The success rate for primary angioplasty is lower and the mortality rate higher than in the trials. It is clear though that very few centres have a protocol for the use of infarct angioplasty as their volume of activity in this area is so low. It is likely that angioplasty is therefore being used for relatively high risk patients at present. Another explanation is that the mortality quoted in the trials is lower because of the exclusion criteria for entry to the trial. Only greater experience in this field will determine the outcomes that are appropriate as angioplasty is offered to unselected populations of patients.

Clinical audit is essentially an exercise in determining whether we are doing something to the highest possible standards. The present government's support of clinical audit processes should not appear as a threat. BCIS is of 
the view that the present climate will allow departments to create an infrastructure that will enable clinicians to review their results and to identify areas requiring change. BCIS strongly supports the concept of the CCAD. This should provide the vehicle for a much more sophisticated audit exercise, both on a national scale, and for individual departments and operators. BCIS aims to use this process to examine the four features required to perform angioplasty optimally, namely, structure, appropriateness, process, and outcome. In other words, BCIS will continue to look at the facilities and the staffing levels relating to angioplasty, attempt to ensure that it is applied to appropriate patients, examine the methodologies that are used for angioplasty, and to identify the outcome of patients undergoing procedures. To date, BCIS has been able to examine the infrastructure for coronary interventions and has partially analysed the process, but good outcome data have been lacking and there has been virtually no analysis of the appropriateness of interventions.

The CCAD pilot project, which is discussed elsewhere in this supplement, ${ }^{6}$ has shown that centres can collect and transmit data to a central database. Many lessons have been learned. There are certain gaps in the process that are currently being evaluated, namely the ability to verify or validate data, the methodologies needed to analyse data, and the mode of feedback to individual departments and operators. BCIS is keen that the CCAD project is rolled out to all units in the UK, and it is likely that the Department of Health will mandate all purchasing authorities and trusts to cooperate.

Audit requires accurate data collection. It is proposed that BCIS uses CCAD to accredit hospitals as capable of providing accurate data-that is, provide a method of medical quality assurance. This will be a prerequisite to BCIS being able to review data and establish standards. BCIS will continue a policy of identifying centres that do not provide data.

The audit process is a means of providing the best care to our patients. Inherent in any audit process is the realisation that some deficiencies may be found and methods will be needed to correct them. Feedback to those directly responsible for the standards of angioplasty in each department will enable problems to be detected early and for appropriate steps to be made if there are areas of concern. In addition to annual feedback, BCIS proposes a standards monitoring committee to help in the review process. Lastly, BCIS believes that the CCAD process will also allow greater collaboration with our European colleagues who are also examining audit methods.

\section{Recommendations}

TRUSTS AND HEALTH AUTHORITIES

(1) All departments and trusts should demand an audit process for coronary intervention and support their cardiologists in establishing the infrastructure required to cooperate with the BCIS/CCAD process.
(2) Trusts must provide the information technology as well as audit and data personnel necessary for this.

(3) Departmental data collection systems must be CCAD compatible. Compatibility with the CCAD system means being able to collect the data, but in addition, departments will have to adhere to CCAD specifications required for encryption of data to keep it secure and transmission to a central database.

\section{DATA COLLECTION}

(1) Cardiac departments in revascularisation centres should identify and employ key personnel for audit purposes in the field of coronary intervention.

(2) Individual departments need to liaise with trust or hospital information technology departments to ensure that the appropriate level of computer hardware and software is available for this purpose.

(3) All units should use the variables listed in the BCIS/CCAD intervention dataset. Ideally all data ("core" and "additional") should be collected, but at the very least the "core" data must be made available for each patient.

(4) All departments should have a policy for taking blood for cardiac enzyme evaluation 6-8 hours after and the morning after a coronary intervention, to enable BCIS to determine accurately the incidence of myocardial infarction following a procedure. At present, BCIS requires measurement of creatine phosphokinase (CPK) and creatine kinase-MB, the latter being required for all patients with a raised CPK.

(5) For consistency, all centres should report on outcome related to the in-patient stay during the patient's admission for angioplasty. BCIS should not be provided with data that only relates to the procedure itself, nor should it receive data relating to 30 day or other arbitrary periods following angioplasty.

(6) Until the development of a UK central database, BCIS will continue to ask for annual reports from all centres. If the BCIS/CCAD dataset is used, departments will be able to provide complete and accurate information for analysis.

BCIS/CCAD

(1) BCIS will establish a better means of auditing coronary intervention procedures in the UK. The methodology pertaining to coronary intervention will be established before looking at non-coronary interventions.

(2) BCIS will provide consistent definitions of variables used in the datasets.

(3) BCIS will introduce and distribute a scoring system for coronary artery anatomy to aid the audit of appropriateness and outcomes of coronary interventions.

(4) BCIS will distribute the datasets, definitions, and coronary scoring system to all coronary intervention centres. 
(5) BCIS will distribute a specification for CCAD compatibility to all centres.

(6) BCIS, through CCAD, will accredit centres with appropriate means of data collection but will continue a policy of identifying centres with inadequate data collection processes.

(7) BCIS will continue to support the CCAD project and will support its rollout to all UK coronary intervention centres. BCIS recognises that resources will be required to complete this project and will work with CCAD to establish the mechanism for its implementation.

(8) BCIS, through CCAD, will establish a method for data verification.

(9) During the transition from the present method of data collection to a universal CCAD process, BCIS will continue to collect data in a format that will analyse case mix in an individual department.
(10) BCIS will establish methods of analysing data and reporting back to all centres.

(11) BCIS will establish a standards monitoring committee to help in the review process.

1 Hubner PJB, for Council of the British Cardiovascular Intervention Society. Cardiac interventional procedures in the United Kingdom during 1988. Br Heart f 1990;64:367 .

2 Hubner PJB, for Council of the British Cardiovascular Intervention Society. Cardiac interventional procedures in the United Kingdom in 1989. Br Heart f 1991;66:469-71.

3 Hubner PJB, for Council of the British Cardiovascular Intervention Society. Cardiac intervention procedures in the United Kingdom in 1990, Br Heart f 1992:68:434-6.

4 Council of the British Cardiovascular Intervention Society. Cardiac intervention procedures in the United Kingdom in 1991. Br Heart 7 1993;70:201-3.

5 Gray HH, on behalf of the Council of the British Cardiovascular Intervention Society. Cardiac interventional procedures in the United Kingdom 1992 to 1996. Heart 1999;82(suppl II):II10-17.

6 Rickards A, Cunningham D. From quantity to quality: the central cardiac audit database project. Heart 1999;82 (suppl II):II18-22. 